\title{
Transplant surgery and the obese patient: special considerations
}

This article was published in the following Dove Press journal:

Transplant Research and Risk Management

4 December 2015

Number of times this article has been viewed

\section{Prince Mohan \\ Manish Kadian \\ Titte R Srinivas}

Division of Nephrology, Department of Medicine, Medical University of South Carolina, Charleston, SC, USA
Correspondence: Titte R Srinivas Division of Nephrology, Department of Medicine, Medical University of South Carolina, 96 Jonathan Lucas Boulevard, Room 819, Charleston, SC 29464, USA Email srinivat@musc.edu
Abstract: Perhaps as a consequence of increased obesity in the general population, the likelihood of obese patients receiving kidney transplants has more than doubled. Obesity confers increased risk for graft loss and death among renal transplant recipients. However, the relationship of changes in body weight and composition to outcome on the transplant waitlist and posttransplantation are not straightforward. Strategies to manage weight in the waitlisted and post-kidney transplantation patient must be performed in the context of a multidisciplinary approach and individualized to risk factors in particular patients. While retrospective studies offer considerable insight into the relationship between obesity and kidney transplant outcome, causal inferences must be made with great caution.

Keywords: kidney transplant, obesity, delayed graft function, new onset diabetes after transplant, transplant outcomes

\section{Introduction}

Obesity is an increasingly common comorbidity in patients with chronic renal diseases with up to $60 \%$ of patients being obese or overweight at the time of transplant. ${ }^{1}$ The weight gain 1 year after successful renal transplantation averages approximately $8 \mathrm{~kg}{ }^{2}$

We discuss the impact of both pretransplant obesity and posttransplant obesity on outcomes following renal transplantation. We offer general guidelines that may help the treating physician manage the obesity in the context of optimizing graft and patient survival.

\section{Definitions}

The most widely accepted classification of obesity is based on the anthropometric parameter body mass index (BMI), defined as body weight in kilograms divided by height in meters squared. BMIs between 18.5 and $24.9 \mathrm{~kg} / \mathrm{m}^{2}$ represent normal weight, BMIs between 25 and $29.9 \mathrm{~kg} / \mathrm{m}^{2}$ overweight, and BMIs greater than $30 \mathrm{~kg} / \mathrm{m}^{2}$ obesity. Cause-specific mortality such as cardiovascular $(\mathrm{CV})$ death starts rising with BMIs exceeding $25 \mathrm{~kg} / \mathrm{m}^{2}{ }^{3}$ Much of the literature examining the relationship between BMI and mortality suggests a curvilinear relationship where mortality risk is highest among the heaviest and the leanest. ${ }^{3}$

Abdominal obesity, defined by a waist-hip ratio $>0.9$ in women and $>1.0$ in men connotes the preponderance of intraabdominal fat in the adiposity. This phenotype is associated with a greater prevalence of the most important complications of obesity, namely hypertension (HTN), insulin resistance, diabetes, and hyperlipidemia in men and women, as well as addition hyperandrogenism in women. One study suggests that 
the waist-hip ratio as a classifier of the pattern of adiposity may also be more useful than just the BMI in transplanted patients. ${ }^{4}$ BMI unfortunately does not provide information about muscle mass and body composition. Compounding this issue further is that increased adiposity, even among longterm survivors of kidney transplants with good renal function, is accompanied by relatively low muscle mass. ${ }^{5}$

\section{Epidemiology}

The prevalence of obesity continues to increase globally and in developed countries it can be as high as $20 \% .{ }^{6}$ In the USA, $34.9 \%$ of adults aged $>20$ years are obese. ${ }^{7}$ The prevalence of obesity in the kidney transplant population has more than doubled. ${ }^{1}$ Several factors may account for these trends: 1) increased transplantation among older type 2 diabetics, most of whom are obese; ${ }^{1}$ 2) improved management of end-stage renal disease (ESRD) with better preservation of nutrition and hence weight gain during dialysis; ${ }^{1} 3$ ) improved sense of wellbeing after transplantation with an increase in appetite and hence food intake and weight; and 4) declining levels of physical activity as a secular trend. ${ }^{8}$ In the chronic renal failure and dialysis populations from whom transplant candidates are selected, obese patients in contrast to their leaner counterparts tend to exhibit fewer manifestations of protein energy malnutrition. ${ }^{9}$ It has also been demonstrated that hemodialysis patients with decreased baseline fat and decreasing body fat over time have increased mortality. ${ }^{10}$ This observation points to better survival in this population where malnutrition and its inevitable accompaniment, infection, is one of the major contributors to death. This phenomenon stands in direct opposition to the situation in the general population where obesity is clearly a risk factor for excess $\mathrm{CV}$ mortality, often termed the risk factor paradox or reverse epidemiology of obesity in uremia. ${ }^{9}$ In contrast to the relationship of BMI to mortality in the ESRD population, higher BMIs have been shown to be associated with increased patient mortality in transplantation, a pattern similar to that observed in the general population. ${ }^{11}$

\section{Pathophysiologic considerations}

In the general population, obesity portends poor health and longevity as it is an independent risk factor for CV disease and clusters almost inextricably with other risk factors for CV disease and progressive renal insufficiency such as HTN, hyperlipidemia, and insulin resistance. ${ }^{12}$ Obesity is also independently associated with abnormalities of coronary circulation in the population at large. ${ }^{12}$ Obesity has been linked to the development of focal and segmental glomeru- losclerosis and obesity-related glomerulopathy characterized by glomerulomegaly with proteinuria and progressive loss of renal function. In addition, obesity has been implicated in the progression of primary renal disease in the general population. ${ }^{13,14}$ Proteinuria and progressive renal insufficiency have been reported in obese patients undergoing nephrectomy for reasons other than kidney donation. ${ }^{15}$ Given that in the transplant patient hyperfiltration is a necessary and given accompaniment of functional adaptation, obesity could potentially be implicated in posttransplant renal dysfunction. ${ }^{16}$ A number of factors can mediate decreased long-term renal allograft survival. ${ }^{17}$

Increased BMI has been linked to decreased short-term graft survival. ${ }^{18}$ Increased BMI at transplantation could potentially decrease long-term allograft survival by adverse effects on patient survival or by independent effects on the allograft itself. Obesity has been associated with a prothrombotic and inflammatory state that could impact early graft function leading to delayed graft function (DGF). ${ }^{19,20}$ Independent effects of obesity on the allograft could in turn be due to either increased metabolic demand (donor/recipient size disparity) or potentially relate to immunosuppressant drug concentrations. ${ }^{16,21}$ Initial dosing of the calcineurin inhibitors (CNIs) with their attendant nephrotoxic effects may be determined by body weight, thereby increasing the potential for relative overdosing in some instances. ${ }^{22,23}$

\section{Obesity and its impact on short-term sequelae of renal transplantation Perioperative complications}

In the general population, obesity does increase the risk of perioperative complications such as deep vein thrombosis, delayed wound healing, wound infections, and hernias. ${ }^{24}$ These risks can be logically expect to transfer to the ESRD patients with the reasonable expectation that malnutrition, immunosuppression, and coexisting $\mathrm{CV}$ morbidity could compound the overall risk.

The risk of wound infections in recipients with BMIs exceeding $30 \mathrm{~kg} / \mathrm{m}^{2}$ is increased fourfold compared to normal-weight group. ${ }^{25,26}$ Obese transplant subjects also have an increased incidence of reintubation and intensive care unit admission and increased length of hospital. ${ }^{24,27}$

\section{Early complications}

DGF and acute rejection are two significant complications in the early posttransplant period (summary provided in Table 1). 
Table I Early complications: studies and possible mechanisms

\begin{tabular}{|c|c|c|}
\hline Complications & Studies & $\begin{array}{l}\text { Possible mechanisms explaining relationship } \\
\text { of outcome to obesity }\end{array}$ \\
\hline \multirow[t]{5}{*}{ Delayed graft function } & I. Gill et $\mathrm{al}^{28}$ & Operating time and prolonged revascularization due \\
\hline & 2. Modlin et $\mathrm{al}^{29}$ & to anatomic constraints \\
\hline & 3. Meier-Kriesche et $\mathrm{al}^{3 !}$ & No reason mentioned \\
\hline & 4. Molnar et $\mathrm{al}^{19}$ & Higher prothrombotic and inflammatory state \\
\hline & 5. Curran et $\mathrm{al}^{32}$ & Technical challenges, prothrombotic state \\
\hline \multirow[t]{4}{*}{ Acute rejections } & Curran et $\mathrm{al}^{32}$ & Inadequate exposure to calcineurin inhibitors \\
\hline & & Increased warm ischemia time \\
\hline & & Possible issues of weight make dosing challenging especially \\
\hline & & of induction agent, specifically, rabbit antithymocyte globulin \\
\hline Post transplantation hypertension & Kasiske et $\mathrm{al}^{36}$ & Retrospective study, no mechanisms provided \\
\hline
\end{tabular}

The role of obesity in the development of DGF (usually defined as requirement for dialysis in the 1st week after renal transplantation) is uncertain. Single-center studies of cadaveric renal transplantation showed an increased DGF risk with BMIs exceeding $36 \mathrm{~kg} / \mathrm{m}^{2}$. Explanations for the association between recipient obesity and DGF include prolonged total operating time and prolonged revascularization due to anatomic constraints. ${ }^{28,29}$ Other studies do not report an association between obesity and DGF. ${ }^{30} \mathrm{In}$ an analysis of primary adult renal transplants reported to the United States Renal Data System (USRDS), BMIs in excess of $36 \mathrm{~kg} / \mathrm{m}^{2}$ conferred an increased risk for DGF (relative risk $[R R]=1.51 ; 95 \%$ confidence interval $[\mathrm{CI}] 1.27-1.85$ ). No significant associations between BMI and acute rejection episodes were noted in this study. ${ }^{31}$ In a study of more than 11,000 patients whose BMIs on dialysis were known, obesity was reported as an independent correlate of DGF. The average BMI of those with DGF in this study was 28.0 $\mathrm{kg} / \mathrm{m}^{2}$ vs $26.6 \mathrm{~kg} / \mathrm{m}^{2}$ among those without DGF. The relative odds of DGF with increasing BMI was 1.3 compared to the reference group of those with BMIs of $22-24 \mathrm{~kg} / \mathrm{m}^{2} .^{19}$ A study by Curran et al showed increasing proportion of patients with DGF as BMI increased (proportion of patients with DGF in the $<20,20-24.9,25-29.9,30-34.9$, and $>35$ $\mathrm{kg} / \mathrm{m}^{2}$ BMI groups were $15.3 \%, 17.5 \%, 19.3 \%, 25.5 \%$, and $37.2 \%$, respectively, $P<0.001) .{ }^{32}$ Unfortunately, none of these studies examined the use of depleting antibody induction or machine perfusion of kidneys, both of which could influence the incidence and clinical course of DGF. In summary, recipient obesity may predispose to DGF especially at the upper extreme of obesity.

The relationship between early DGF and long-term graft loss is not straightforward and may be influenced by better selection and therapeutic management. Nicoletto et al, in a recent meta-analysis, showed that obese patients have increased risk of DGF but also interestingly found that obesity was not a risk factor for graft loss, death by $\mathrm{CV}$ disease, and all-cause mortality in the recent years of transplantation (after 2003). The exact cause of this shift is not known at this time but could be explained by better immunosuppressive regimens, better control of comorbid conditions, and gain of experience in kidney transplantation..$^{33}$

Most older studies did not demonstrate associations between obesity and acute rejection episodes both early and late; $;^{31,34,35}$ however, a recent study suggests that the probability of biopsy proven acute rejection is highest among the obese. This may potentially relate to immunosuppression dosing especially with regard to induction agents. ${ }^{32}$

Post-transplant hypertension (HTN) complicates majority of the transplants (up to $90 \%$ ) in the CNI era. ${ }^{36}$ Pretransplant obesity is a major risk factor for the development and persistence of HTN posttransplantation. Given that HTN is closely tied to graft survival, its occurrence with greater frequency in the obese recipient deserves close attention.

\section{Posttransplant hyperlipidemia}

The etiology of posttransplant hyperlipidemia is multifactorial and includes CNIs, corticosteroid use, genetic predisposition, uncontrolled diabetes mellitus (DM), and other immunosuppressants such as sirolimus. One of the early descriptions of hyperlipidemia in renal transplant patients, and those on dialysis and uremic subjects, noted the contribution of obesity to hyperlipidemia. ${ }^{37,38}$ Carvalho and Soares studied the relationships between BMI and lipid levels in 72 renal transplant recipients. Pretransplant BMIs were greater in the hypercholesterolemic recipients $\left(25.6 \pm 4.1\right.$ vs $23.8 \pm 3.2 \mathrm{~kg} / \mathrm{m}^{2}$; $P=0.04)$. Furthermore, even in this small study, the authors were able to show that the risk of doubling of serum creatinine was significantly higher in the high cholesterol group; no differences in graft loss were noted in the reported follow-up 
period across lipid levels and BMI strata. ${ }^{39}$ It has also been shown that the use of lipid-lowering therapy can lower the incidence of cardiac events in the transplant recipient. ${ }^{40}$ Based on the foregoing information it is probably reasonable to surmise that one must at the very least expect hyperlipidemia in the obese renal transplant recipient and treat it with appropriate measures.

\section{Insulin resistance and new-onset diabetes after transplant}

Obesity is a recognized contributor to the development of insulin resistance and is strongly associated with type II DM in the general population. The association between insulin resistance, obesity, and DM persist after successful transplantation with the added effects of glucocorticoids and CNIs. Both impaired insulin secretion and decreased sensitivity to insulin are the central underpinnings of newonset diabetes after transplant (NODAT). ${ }^{41}$ The incidence of NODAT may be higher in patients treated with tacrolimus than with cyclosporine. Numerous studies have demonstrated that obesity is an independent risk factor in the development of NODAT and that this risk increases with time in the obese transplant recipient. In an analysis of USRDS data, obesity was an independent risk factor for the development of NODAT $(\mathrm{RR}=1.73 ; P<0.0011) .{ }^{42}$ Cosio et al reported that $20 \%$ of 1,811 renal transplant recipients followed for 8 years on average developed NODAT. ${ }^{43}$ Those developing NODAT had significantly higher BMIs at time of transplantation (NODAT: $29 \pm 7 \mathrm{~kg} / \mathrm{m}^{2}$; no NODAT: $25.9 \pm 6.5 \mathrm{~kg} / \mathrm{m}^{2}$; $P<0.001)$. A study looked at 490 kidney transplant recipients who were not diagnosed with diabetes pretransplant, were transplanted between 1998 and 2003, and were followed for up to 4 years. ${ }^{44}$ Within 1 week posttransplant, $45 \%$ of recipients had abnormal fasting blood sugars between 100 and $125 \mathrm{mg} / \mathrm{dL}$ and $21 \%$ had NODAT (fasting blood glucose $\geq 126$ ). At 1 year posttransplant, $33 \%$ of patients had impaired fasting glycemia and $13 \%$ had NODAT. Significant risk factors for hyperglycemia at 1 year included: (along with higher BMI) older recipient, male sex, higher pretransplant blood glucose, and higher blood glucose 1 week posttransplant $(P<0.002$ for each of the risk factors by multivariate analyses). During a follow-up period of up to 4 years, $12 \%$ of recipients suffered $\mathrm{CV}$ events. Increasing fasting glucose levels ( $>100 \mathrm{mg} / \mathrm{dL})$ at 1,4 , and/or 12 months posttransplant were significantly related to $\mathrm{CV}$ events (posttransplant cardiac events $P=0.001$, and peripheral vascular disease events $P=0.003$ ). Furthermore, this relationship between fasting blood sugar and $\mathrm{CV}$ events was independent of all other CV-risk factors, such as older age, pretransplant CV disease or event, male sex, dyslipidemia, and transplant vintage. ${ }^{44}$ Obesity likely contributes to $\mathrm{CV}$ events in transplant recipients through its relationship to metabolic syndrome. Prasad et al compared five definitions of metabolic syndrome and found that the World Health Organization 1998 definition predicted major acute CV events (MACE) 3 months posttransplant as well as time to MACE when comparing metabolic syndrome patients vs non-metabolic syndrome patients. There were 25.3 events/1,000 patient years in metabolic syndrome patients vs 15.5 events/1,000 patient years in non-metabolic syndrome patients. Time to MACE was $5.5 \pm 3.5$ years with metabolic syndrome patients vs $6.8 \pm 3.9$ years without metabolic syndrome $(P<0.0001)$. They also found that among metabolic syndrome components, dysglycemia provided the greatest hazard ratio (HR) for MACE (1.81; 95\% CI 1.26-2.6), increased successively by microalbuminuria (HR 1.946; 95\% CI 1.37-2.75), dyslipidemia (HR 3.284; 95\% CI 1.72-6.26), HTN (HR 4.127; 95\% CI 2.16-7.86), and central obesity (HR 4.282; 95\% CI $2.09-8.86) .{ }^{45}$ Microalbuminuria provided the greatest incremental increase in hazard over dysglycemia alone.

\section{Impact of obesity on graft and patient survival after kidney transplantation}

Does mild obesity affect long-term outcome of solitary renal transplants (Table 2)? This question was addressed in a single-center study of renal transplant recipients performed in the USA. ${ }^{34}$ The risk of graft loss and death were highest in the most obese and the leanest subjects. This is in sharp contrast to the patter seen in the general population. Significant risk factors associated with graft loss were $\mathrm{BMI}>25$ $\mathrm{kg} / \mathrm{m}^{2}$, cadaveric donor status, acute rejection episode, and use of azathioprine as opposed to mycophenolate mofetil. The major cause of death in both BMI groups was infection followed by $\mathrm{CV}$ death with a trend toward more infectious death in the BMI $>25 \mathrm{~kg} / \mathrm{m}^{2}$ group. When censored for death, the major independent risk factor for graft loss was chronic rejection. Death-censored graft loss trended higher in the $\mathrm{BMI}>25 \mathrm{~kg} / \mathrm{m}^{2}$ group independent of race, acute rejection, serum cholesterol, Cyclosporine levels, or other covariates. ${ }^{34}$

To address the hypothesis that obesity affected long-term graft survival independent of patient death, and to investigate the effects of obesity on cause-specific mortality in renal transplantation, an analysis of USRDS data was conducted. ${ }^{31}$ The overarching results are indicated in the Figures 1-5. Risk 
Table 2 Impact of obesity on graft and patient survival: studies and proposed mechanisms

\begin{tabular}{|c|c|c|c|}
\hline & Study & Outcome & $\begin{array}{l}\text { Study critique/proposed } \\
\text { mechanisms in the study }\end{array}$ \\
\hline \multirow[t]{24}{*}{ Graft and patient survival } & Meier-Kriesche et $\mathrm{al}^{34}$ & $\begin{array}{l}\text { Seven-year graft survival worse in patients } \\
\text { with BMI }>25 \mathrm{~kg} / \mathrm{m}^{2}\end{array}$ & Retrospective single-center study \\
\hline & Meier-Kriesche et $\mathrm{al}^{3 \mathrm{I}}$ & Risk of graft failure higher in patients with & USRDS data base study \\
\hline & & $\mathrm{BMI}<18 \mathrm{~kg} / \mathrm{m}^{2}$, and exponentially higher & $(51,927$ patients from 1988 to 1997$)$ \\
\hline & & above $\mathrm{BMI}$ of $36 \mathrm{~kg} / \mathrm{m}^{2}$ & \\
\hline & & Increased patient mortality in patients with & \\
\hline & & $\mathrm{BMI}<18 \mathrm{~kg} / \mathrm{m}^{2}$ and above $34 \mathrm{~kg} / \mathrm{m}^{2}$ & \\
\hline & Gore et $\mathrm{al}^{18}$ & Risk of graft failure highest if $\mathrm{BMI}<18 \mathrm{~kg} / \mathrm{m}^{2}$ & USRDS database study \\
\hline & & and $>35 \mathrm{~kg} / \mathrm{m}^{2}$ & (27,377 patients from 1997-1999) \\
\hline & & Higher death-censored and all-cause & Increased adipocytokines like \\
\hline & & graft failure in patients with BMI $>35 \mathrm{~kg} / \mathrm{m}^{2}$ & leptin play a role* \\
\hline & & No difference in patient survival & Higher levels of transforming \\
\hline & & & growth factor $\beta^{*}$ \\
\hline & & & Higher levels of angiotensin II and \\
\hline & & & plasminogen activator inhibitor I, \\
\hline & & & which cause endothelial injury* \\
\hline & Cannon et $\mathrm{al}^{47}$ & Risk of graft failure higher among patients & USRDS database study that included \\
\hline & & with $\mathrm{BMI}>35 \mathrm{~kg} / \mathrm{m}^{2}$ & 81,329 patients from 2004-2010 \\
\hline & & No difference in patient survival & Greater tendency of obese patients \\
\hline & & & to get deceased donor organ \\
\hline & & & Higher DGF rates \\
\hline & Curran et $\mathrm{al}^{32}$ & Risk of graft failure higher in patients with & Retrospective single-center observational \\
\hline & & $\mathrm{BMI}>35 \mathrm{~kg} / \mathrm{m}^{2}$ & cohort study with I,I5I patients \\
\hline & & Patient survival worse in patients with & Higher DGF and antibody-mediated \\
\hline & & $\mathrm{BMI}>35 \mathrm{~kg} / \mathrm{m}^{2}$ & rejections \\
\hline
\end{tabular}

Note: *Biologically plausible mechanisms mentioned, but cannot be inferred from the data presented.

Abbreviations: BMI, body mass index; DGF, delayed graft function; USRDS, United States Renal Data System.

for graft loss, death, and death-censored graft loss are highest at extremes of BMI.

In contrast to these findings, Howard et al reporting on a single-center study did not show any effects of recipient obesity at the time of transplantation on graft or patient survival; only a higher incidence of posttransplant diabetes was noted in recipients with BMIs exceeding $35 \mathrm{~kg} / \mathrm{m}^{2}$. In this study, it should be pointed out that only 98 patients had BMIs in excess of $30 \mathrm{~kg} / \mathrm{m}^{2}$ as opposed to 457 with BMIs less than $25 \mathrm{~kg} / \mathrm{m}^{2}$ and 278 with BMIs between 25 and $30 \mathrm{~kg} / \mathrm{m}^{2} .^{30}$ These findings could, however, represent lack of power.

With regard to infectious death, there was a very strong association of the RR for this endpoint both with very low and elevated BMIs. Again, the relationship was a curvilinear

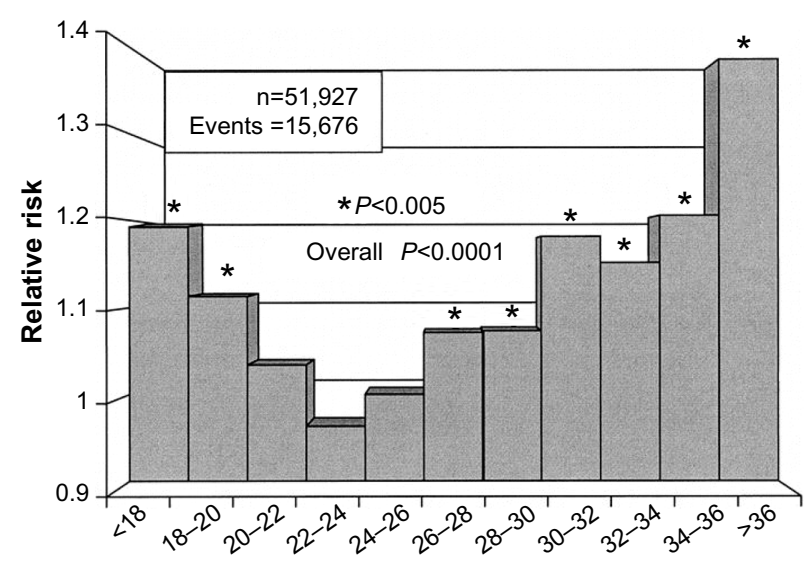

Body mass index $\left(\mathrm{kg} / \mathrm{m}^{2}\right)$

Figure I Relative risk for graft loss by body mass index.

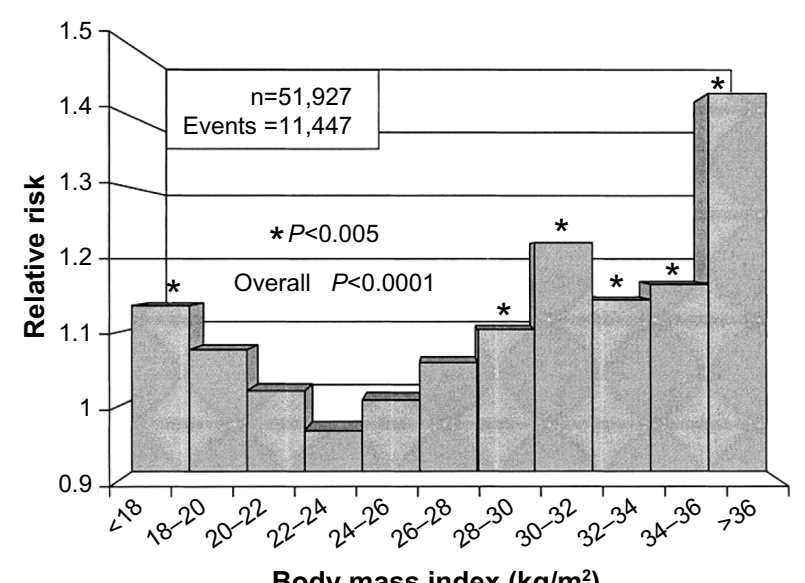

Body mass index $\left(\mathrm{kg} / \mathrm{m}^{2}\right)$

Figure 2 Relative risk for death-censored graft loss by body mass index. 


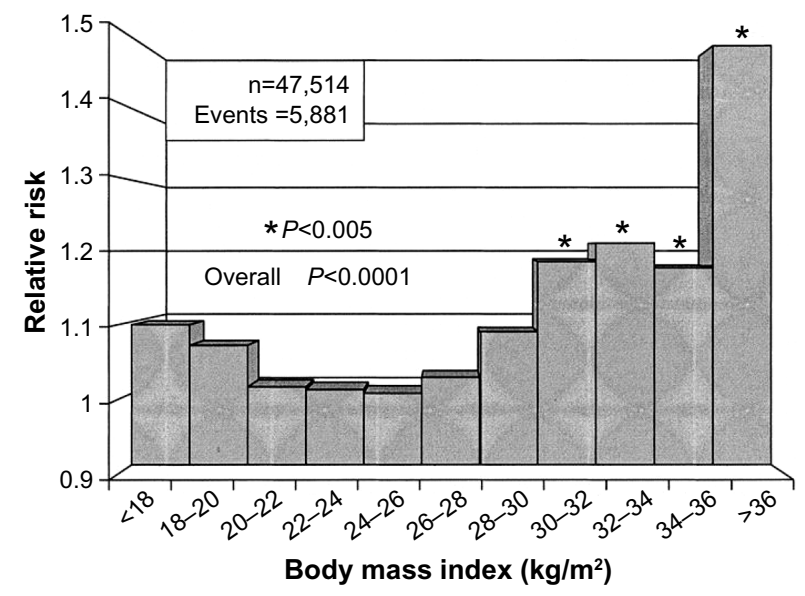

Figure 3 Relative risk for chronic allograft failure by body mass index.

U-shaped one with the interval free of significant risk between BMIs of 22 and $30 \mathrm{~kg} / \mathrm{m}^{2}$ (Figure 6).

Interestingly, BMI was significantly associated with the RR for DGF. The RR for DGF increased gradually with increasing BMI and was greatest for BMIs exceeding $36 \mathrm{~kg} / \mathrm{m}^{2}(\mathrm{RR}=1.51 ; 95 \%$ CI $1.27-1.85)$. For DGF, the BMI $<18 \mathrm{~kg} / \mathrm{m}^{2}$ group exhibited a $22 \%$ lower RR when compared to the reference group ( $\mathrm{RR}=0.78 ; 95 \% \mathrm{CI}$ $0.60-0.98)$. In contrast, no significant association between BMI and the odds ratio for acute rejection episodes within the first 6 months posttransplantation were demonstrable.

This study was thus able to show that recipient BMI is a strong independent risk factor both for patient mortality and graft failure independent of patient death after renal transplantation. As described above, the relationship between BMI and mortality after renal transplantation exhibits a U-shaped pattern that is similar to that observed in the general population. Gore et al using the United Network for Organ

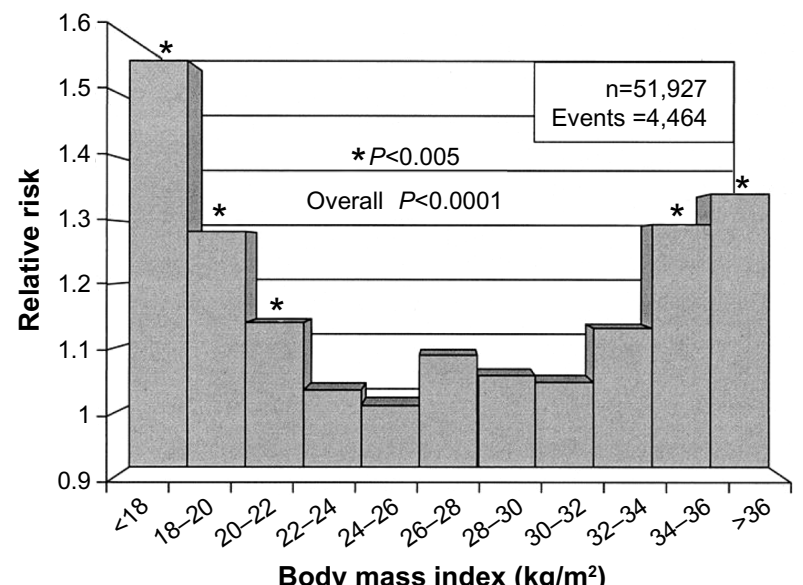

Figure 4 Relative risk for death with functioning graft by body mass index.

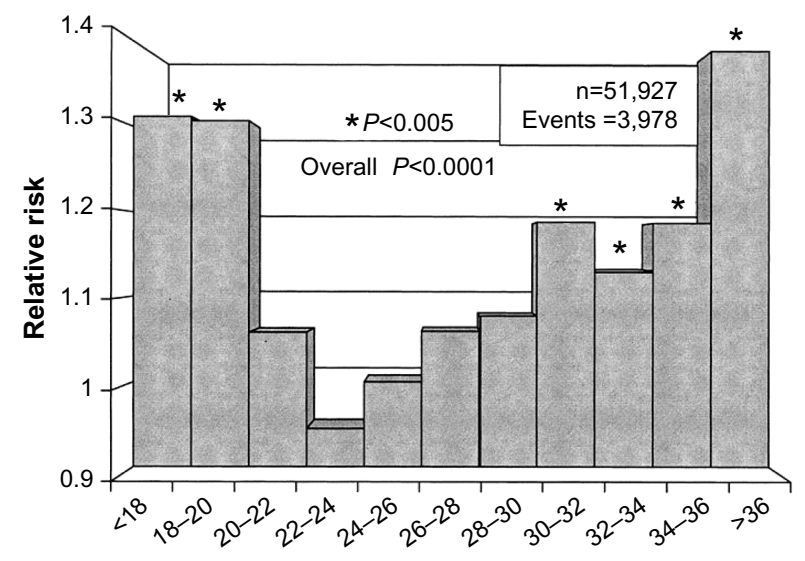

Body mass index $\left(\mathrm{kg} / \mathrm{m}^{2}\right)$

Figure 5 Relative risk for cardiovascular death by body mass index.

sharing (UNOS) database have also shown that obesity in the renal transplant recipient is associated with decreased allograft survival. ${ }^{18}$

A study from Brazil by Moreira et al showed that overweight and obese recipients presented significantly lower estimated glomerular filtration rate (GFR) at 5 years posttransplantation $(P<0.002)$ but no statistically significant differences were found in patients or grafts survivals. Underweight and obese recipients presented a higher incidence of early graft loss. Obese patients 1 year after transplantation have a significantly higher incidence of NODAT and a trend toward a higher incidence of acute rejection in the 5 th year of follow-up. ${ }^{46}$

The UNOS database was examined from 2004 to 2009 to look at the impact of obesity on renal transplantation outcomes. Weight classes were stratified as: non-obese (BMI $<30 \mathrm{~kg} / \mathrm{m}^{2}$ ), class I obese (BMI $\geq 30$ and $<35 \mathrm{~kg} / \mathrm{m}^{2}$ ), class II obese (BMI $\geq 35$ and $<40 \mathrm{~kg} / \mathrm{m}^{2}$ ), and class III obese

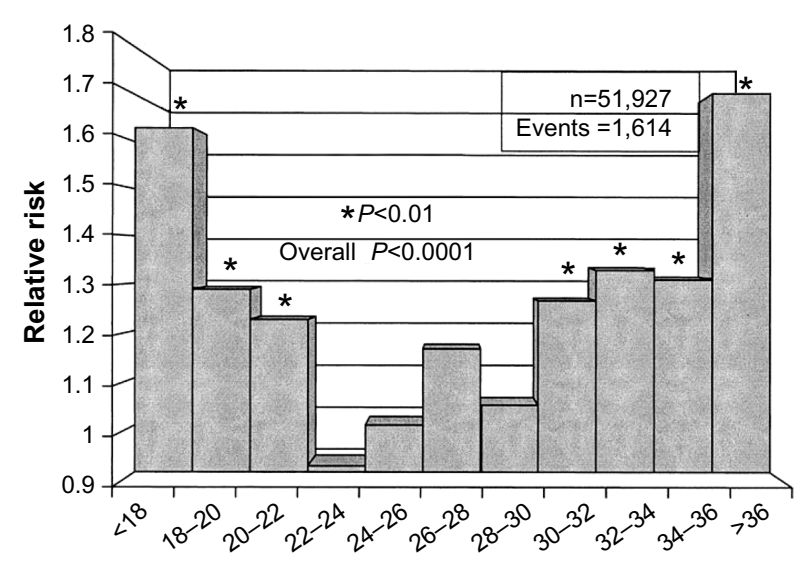

Body mass index $\left(\mathrm{kg} / \mathrm{m}^{2}\right)$

Figure 6 Relative risk for infectious death by body mass index. 
(BMI $\geq 40 \mathrm{~kg} / \mathrm{m}^{2}$ ). Recipient BMI was associated with an increased risk of DGF, with odds ratios of 1.34, 1.68, and 2.68 in the class I obese, class II obese, and class III obese groups, respectively. ${ }^{47}$ After controlling for potential confounders, class I obese patients were interestingly found to have a reduced hazard for death compared with their non-obese counterparts (HR 0.92; $P=0.025$ ) and class II and III were not statistically significantly associated with lower patient survival. ${ }^{47}$ The conclusion was that BMI $>40 \mathrm{~kg} / \mathrm{m}^{2}$ was the strongest independent risk factor for DGF (odds ratio 2.68).

Death-censored graft survival is a parameter that measures graft survival independent of patient death. Thus, relationships of BMI with this parameter do not reflect the overall mortality risk conferred by a mere increase in mortality risk. Given the intrinsic proclivity of the obese to proteinuria, glomerulosclerosis, and progressive loss of renal function, it is quite possible that obesity could be a significant mediator of chronic allograft failure. However, given the close clustering of obesity with comorbidities that can affect the allograft, "purer" effects of obesity that mediate graft loss such as hyperfiltration and a consequent glomerulopathy need to be explored in greater depth.

Armstrong et al have shown in a prospective study of 90 renal transplant recipients followed to 2 years that the prevalence of central obesity, impaired glucose tolerance, hyperlipidemia, and HTN at 2 years increased with increasing BMI. ${ }^{48}$ Importantly, progression of proteinuria over time was strongly associated with increased BMI. Interestingly, in their study, progressive decline in estimated GFR (modified diet in renal disease) was not associated with BMI in the 2-year follow-up. These findings are of considerable interest in that one would expect progression of proteinuria to precede declining GFR if indeed hyperfiltration is a significant mediator of obesity-induced attrition of renal function

\section{Weight gain after transplantation}

\section{Nature of weight gain}

Weight gain following successful kidney transplantation is frequent and occurs in up to $50 \%$ of recipients. In the emaciated recipient it may represent the restoration of appetite and nutrition; in others it may represent the effects of steroidinduced obesity. Steroids have been blamed for most obesity that follows transplantation. However, pretransplant obesity is the major precedent to posttransplant obesity. Other risk factors include younger age, African American race, and female sex. ${ }^{24}$ Weight gain posttransplant in the 1 st year is independent of cumulative steroid dose, donor source, rejection episodes, or posttransplant renal function; after the 1 st year, cumulative steroid dose is the primary determinant of weight gain. ${ }^{49,50}$ The relationship between steroid use and weight gain posttransplantation has been eloquently illustrated in a randomized controlled trial comparing early corticosteroid withdrawal with maintenance corticosteroids ( $5 \mathrm{mg} /$ day of prednisone). The mean change in body weight at 5 years among those on steroids averaged $7 \mathrm{~kg}$ and was not significantly different between the groups. ${ }^{51}$

\section{Does weight gain affect outcomes?}

While obesity and overweight at the time of transplantation affect outcome, less is known about outcomes when weight gain follows transplantation. Feldman et al, in a cohort study conducted between 1985 and 1990 with up to 5 years of follow-up, reported that the adjusted RR of allograft failure for a $15 \mathrm{~kg}$ increase in recipient body weight was 1.47, $P<0.0001$ (95\% CI 1.21-1.78) and the adjusted RR for a 10-unit increase in recipient BMI was 2.34, $P<0.0001$ $(95 \%$ CI $1.53-3.58){ }^{52}$

The complexity of these issues has been underscored in recent years by studies that have merged patient-level data from a large dialysis organization in the USA with posttransplant data. The advantage of this novel approach is the linking of rich, granular patient-level data with Scientific Registry of Transplant Patients data. ${ }^{19}$ Predialysis creatinine values averaged over a 13-week period were used as surrogates of muscle mass. Postdialysis body weights were used to compute BMIs. Compared to patients with pretransplant 3-monthaveraged serum creatinine of $8-10 \mathrm{mg} / \mathrm{dL}$, those with 3 -month-averaged serum creatinine of $<4 \mathrm{mg} / \mathrm{dL}$ exhibited a 2.2-fold higher risk of achieving the combined outcome of death or graft failure whereas those with time-averaged creatinine of $14 \mathrm{mg} / \mathrm{dL}$ or above exhibited $22 \%$ better graft and patient survival..$^{53}$ In another study using the same database, Molnar et al examined the association of BMI with weight loss and mortality among waitlisted hemodialysis patients censored at the time of transplantation. ${ }^{54}$ They showed that each $1 \mathrm{~kg} / \mathrm{m}^{2}$ increase in BMI was associated with a relative hazard for death of 0.96 (95\% CI 0.95-0.97). Compared to the lowest creatinine quintile, the fourth and fifth quintiles exhibited lower relative hazard for death (fourth quintile, HR 0.75; 95\% CI 0.66-0.86; fifth quintile, HR 0.57; 95\% CI 0.49-0.66). Compared to those with minimal weight change, ie, less than $\pm 1 \mathrm{~kg}$ over a 6 -month period, those with 3-5 $\mathrm{kg}$ and $\geq 5 \mathrm{~kg}$ weight loss exhibited significantly increased relative hazard for death at 1.31 (95\% CI 1.14-1.52) and 1.51 ( 95\% CI 1.30-1.75), respectively. Similar associations were observed with regard to creatinine changes over time. 
The authors concluded that waitlisted patients with lower BMI or muscle mass, and/or unintentional weight loss or loss of muscle mass, may be at increased risk for death on the waitlist. Several issues need to be pondered with regard to these conclusions. ${ }^{55}$ The first is that the exact basis for weight loss or gain in such observational studies (ie, whether intentional or reflective of disease processes such as uremic cachexia, malignancy, overall debility, or infection) cannot be discerned. The next concern surrounds the method of censoring at the time of transplantation. This has the potential to bias the results as those patients who lost or gained weight rapidly may well have been considered unfit for transplant and could well have remained waitlisted but not considered active, and thus were never transplanted. Lastly, large shifts in body weight may well reflect shifts in volume status which could reflect underlying issues either related to compliance or heart failure. ${ }^{55}$

\section{An approach to obesity in the transplant recipient}

Given the foregoing discussion, the obese ESRD patient presenting for transplantation presents a profile that is $\mathrm{CV}$ risk prone if not actually already burdened with established $\mathrm{CV}$ disease. With this in mind, the pretransplant evaluation should include a diligent search for and appropriate management of coronary artery disease. Most transplant institutions screen for coronary artery disease with noninvasive tests such as radionuclide stress tests and may proceed directly to coronary angiography in high risk subjects such as diabetics and those with previous history of coronary events. Optimal management of hyperlipidemia, HTN, and diabetes should be instituted and maintained through the time that the patient waits for the transplant. The surgical evaluation is focused on aspects that can impinge on the occurrence of postoperative complications such as hernias and wound dehiscence. This may play a role in regimen selection since certain drugs such as sirolimus may be associated with a higher rate of poor wound healing. Surgeons and nephrologists should inform men and women in a similar manner about the risks of obesity related with kidney transplantation. ${ }^{56}$ Pre-anesthesia screening should focus on risks for venous thrombosis and ventilatory failure such as preexisting sleep apnea.

Whether patients should be made to lose weight before transplantation is certainly not clear. Despite the unfavorable effects of obesity on transplant outcome, a high BMI in the dialysis patient is not associated with a universally poor outcome. Importantly, this "risk factor paradox" needs to be kept in mind when one takes into account that most transplant centers either arbitrarily exclude recipients with BMIs in excess of $30 \mathrm{~kg} / \mathrm{m}^{2}$ or certainly delay a transplant until a recipient can reach some predefined (oftentimes arbitrary) weight target, despite overwhelming and incontrovertible evidence demonstrating the survival advantage of transplantation over dialysis even in the obese. That renal transplantation continues to confer a survival advantage even in the obese patient was reported by Glanton et al using USRDS data. In comparison to maintenance dialysis, both recipients of solitary cadaveric kidneys (HR 0.39; 95\% CI $0.33-0.47$ ) and recipients of living-donor kidneys (HR 0.23 ; 95\% CI 0.16-0.34) had statistically significant improved survival. However, these benefits did not apply to those patients with BMI $\geq 41 \mathrm{~kg} / \mathrm{m}^{2}$ (HR $0.47 ; 95 \% \mathrm{CI}$ $0.17-1.25 ; P=0.13) .{ }^{57}$

We submit that every transplant center has had experience with obese candidates and that certainly successful transplantation has been reported in morbidly obese subjects.

If dietary interventions for weight loss are to be instituted, these should be done in a supervised setting with monitoring of nutritional status using markers such as prealbumin under the guidance of a physician and the active participation of an experienced dietician. Bariatric surgery should be considered in appropriate candidates who have been adequately worked for absence of CV disease with appropriate counseling as to complications, including oxalate nephropathy, nephrolithiasis, ${ }^{58}$ and diligent attention to expected variability in pharmacokinetics.

In the immediate postoperative period, close attention needs to be paid to prevention of wound infections and deep vein thrombosis. Early ambulation with active institution of physiotherapy at the bedside should be utilized.

The successfully transplanted patient is justifiably elated with the lifting of the dietary sanctions engendered by uremia. In addition, high-dose steroids induce a hyperphagic state and promote the development of obesity. Most patients can be counseled about these changes pretransplant to prevent inordinate gains of weight.

Management of obesity after transplantation is best carried out using a multidisciplinary approach that includes behavior modification, exercise counseling, and extensive and continuing nutritional counseling with appropriate use of group support techniques.

Drugs used to study obesity in the general population have not been well studied in the transplant setting. Sibutramine is of concern given its propensity to raise blood pressure, and orlistat can interfere with intestinal absorption of cyclosporine. ${ }^{59}$ 
Non-insulin dependent diabetes associated with obesity can be managed by using sulfonylureas and thiazolidinediones. The propensity for fluid retention with the latter must be kept in mind. When appropriate, insulin should be used. These interventions should best be managed in close consultation with or by an endocrinologist experienced in the care of the transplant recipient.

Hyperlipidemia is managed in the usual fashion with statins or fibric acid derivatives and dietary intervention. Given the overall CV risk in these patients, nonselective beta blockers are used to treat HTN. ACE inhibitors are introduced as early as feasible in these subjects and may well forestall progression of proteinuria. ${ }^{60}$

Management of immunosuppression should pay diligent attention to adherence to tapering of corticosteroids as per protocol. If subjects have had bariatric surgery, absorption of immunosuppressants may be erratic and may require parenteral administration guided by levels. ${ }^{61}$

In the longstanding obese patient with a transplant, the same multidisciplinary approach should be instituted. Patients desiring to come off steroids should be counseled on the lack of evidence supporting considerable weight loss with this as the sole approach and the definite evidence of increased rejection risk with late steroid withdrawal. The lack of benefit of early corticosteroid avoidance with regard to weight gain has been alluded to above and even with this approach, as noted above, the risk of acute rejection is higher, placing into question the merit of this approach to mitigate weight gain.

In summary the obese renal transplant patient presents a considerable clinical challenge. Obesity compounds perioperative risk and is associated with or may lead to many medical complications of transplantation such as obesity, diabetes, and HTN. Obesity compounds the CV risk accrued by the renal transplant recipient. Obesity is also associated with chronic graft loss, the mechanisms underlying which are not entirely clear. Whether obese patients on the transplant waiting list should lose weight prior to being transplanted or listed for transplantation is a subject of controversy. The optimal management of obesity in renal transplantation and the definition of optimal pathways to minimize risk in this population are works in progress.

Thus, even though obesity is a strong risk factor for graft loss, there is no evidence to suggest that weight loss prior to renal transplantation has a beneficial impact on graft survival. It does remain possible that complication rates can be positively affected by pretransplant weight loss. However, given the negative impact of extended waiting time on dialysis, and the potential nutritional hazard of significant weight loss on dialysis, aggressive weight loss programs may not be justified prior to renal transplantation.

\section{Disclosure}

The authors report no conflicts of interest in this work.

\section{References}

1. Friedman AN, Miskulin DC, Rosenberg IH, Levey AS. Demographics and trends in overweight and obesity in patients at time of kidney transplantation. Am J Kidney Dis. 2003;41(2):480-487.

2. Johnson CP, Gallagher-Lepak S, Zhu YR, et al. Factors influencing weight gain after renal transplantation. Transplantation. 1993;56(4): 822-827.

3. Calle EE, Thun MJ, Petrelli JM, Rodriguez C, Heath CW Jr. Body-mass index and mortality in a prospective cohort of US adults. N Engl J Med. 1999;341(15):1097-1105.

4. Kovesdy CP, Czira ME, Rudas A, et al. Body mass index, waist circumference and mortality in kidney transplant recipients. Am J Transplant. 2010;10(12):2644-2651.

5. Schutz T, Hudjetz H, Roske AE, et al. Weight gain in long-term survivors of kidney or liver transplantation - another paradigm of sarcopenic obesity? Nutrition. 2012;28(4):378-383.

6. Gregg EW, Cheng YJ, Cadwell BL, et al. Secular trends in cardiovascular disease risk factors according to body mass index in US adults. JAMA. 2005;293(15):1868-1874.

7. Ogden CL, Carroll MD, Kit BK, Flegal KM. Prevalence of childhood and adult obesity in the United States, 2011-2012. JAMA. 2014;311(8): 806-814.

8. French SA, Story M, Jeffery RW. Environmental influences on eating and physical activity. Annu Rev Public Health. 2001;22:309-335.

9. Fleischmann EH, Bower JD, Salahudeen AK. Risk factor paradox in hemodialysis: better nutrition as a partial explanation. ASAIO J. 2001;47(1):74-81.

10. Kalantar-Zadeh K, Kuwae N, Wu DY, et al. Associations of body fat and its changes over time with quality of life and prospective mortality in hemodialysis patients. Am J Clin Nutr. 2006;83(2):202-210.

11. Ahmadi SF, Zahmatkesh G, Streja E, et al. Body mass index and mortality in kidney transplant recipients: a systematic review and metaanalysis. Am J Nephrol. 2014;40(4):315-324.

12. Schindler TH, Cardenas J, Prior JO, et al. Relationship between increasing body weight, insulin resistance, inflammation, adipocytokine leptin, and coronary circulatory function. J Am Coll Cardiol. 2006;47(6): $1188-1195$.

13. Bonnet F, Deprele C, Sassolas A, et al. Excessive body weight as a new independent risk factor for clinical and pathological progression in primary IgA nephritis. Am J Kidney Dis. 2001;37(4):720-727.

14. Kambham N, Markowitz GS, Valeri AM, Lin J, D’Agati VD. Obesityrelated glomerulopathy: an emerging epidemic. Kidney Int. 2001;59(4): $1498-1509$.

15. Praga M, Hernández E, Herrero JC, et al. Influence of obesity on the appearance of proteinuria and renal insufficiency after unilateral nephrectomy. Kidney Int. 2000;58(5):2111-2118.

16. Brenner BM, Cohen RA, Milford EL. In renal transplantation, one size may not fit all. J Am Soc Nephrol. 1992;3(2):162-169.

17. Kaplan B, Srinivas TR, Meier-Kriesche HU. Factors associated with long-term renal allograft survival. Ther Drug Monit. 2002;24(1):36-39.

18. Gore JL, Pham PT, Danovitch GM, et al. Obesity and outcome following renal transplantation. Am J Transplant. 2006;6(2):357-363.

19. Molnar MZ, Kovesdy CP, Mucsi I, et al. Higher recipient body mass index is associated with post-transplant delayed kidney graft function. Kidney Int. 2011;80(2):218-224.

20. Heinbokel T, Floerchinger B, Schmiderer A, et al. Obesity and its impact on transplantation and alloimmunity. Transplantation. 2013;96(1):10-16. 
21. Dunn TE, Ludwig EA, Slaughter RL, Camara DS, et al. Pharmacokinetics and pharmacodynamics of methylprednisolone in obesity. Clin Pharmacol Ther. 1991 May;49(5):536-549.

22. Rodrigo E, de Cos MA, Sánchez B, et al. High initial blood levels of tacrolimus in overweight renal transplant recipients. Transplant Proc. 2005;37(3):1453-1454.

23. Shibata N, Hoshino N, Minouchi T, et al. Relationship between area under the concentration versus time curve of cyclosporin A, creatinine clearance, hematocrit value, and other clinical factors in Japanese renal transplant patients. Int J Clin Pharmacol Ther. 1998;36(4):202-209.

24. Johnson DW, Isbel NM, Brown AM, et al. The effect of obesity on renal transplant outcomes. Transplantation. 2002;74(5):675-681.

25. Humar A, Ramcharan T, Denny R, Gillingham KJ, Payne WD, Matas AJ. Are wound complications after a kidney transplant more common with modern immunosuppression? Transplantation. 2001;72(12): 1920-1923.

26. Chung H, Lam VW, Yuen LP, et al. Renal transplantation: better fat than thin. J Surg Res. 2015;194(2):644-652.

27. Bennett WM, McEvoy KM, Henell KR, Valente JF, Douzdjian V. Morbid obesity does not preclude successful renal transplantation. Clin Transplant. 2004;18(1):89-93.

28. Gill IS, Hodge EE, Novick AC, Steinmuller DR, Garred D. Impact of obesity on renal transplantation. Transplant Proc. 1993;25(1 Pt 2): 1047-1048

29. Modlin CS, Flechner SM, Goormastic M, et al. Should obese patients lose weight before receiving a kidney transplant? Transplantation. 1997;64(4):599-604.

30. Howard RJ, Thai VB, Patton PR, et al. Obesity does not portend a bad outcome for kidney transplant recipients. Transplantation. 2002;73(1): 53-55.

31. Meier-Kriesche HU, Arndorfer JA, Kaplan B. The impact of body mass index on renal transplant outcomes: a significant independent risk factor for graft failure and patient death. Transplantation. 2002;73(1):70-74.

32. Curran SP, Famure O, Li Y, Kim SJ. Increased recipient body mass index is associated with acute rejection and other adverse outcomes after kidney transplantation. Transplantation. 2014;97(1):64-70.

33. Nicoletto BB, Fonseca NK, Manfro RC, Gonçalves LF, Leitão CB, Souza GC. Effects of obesity on kidney transplantation outcomes: a systematic review and meta-analysis. Transplantation. 2014;98(2):167-176.

34. Meier-Kriesche HU, Vaghela M, Thambuganipalle R, Friedman G, Jacobs M, Kaplan B. The effect of body mass index on long-term renal allograft survival. Transplantation. 1999;68(9):1294-1297.

35. Merion RM, Twork AM, Rosenberg L, et al. Obesity and renal transplantation. Surg Gynecol Obstet. 1991;172(5):367-376.

36. Kasiske BL, Anjum S, Shah R, et al. Hypertension after kidney transplantation. Am J Kidney Dis. 2004;43(6):1071-1081.

37. Kasiske BL; K/DOQI Dyslipidemia Work Group. Clinical practice guidelines for managing dyslipidemias in kidney transplant patients. Am J Transplant. 2005;5(6):1576.

38. Rao KV, Andersen RC. Long-term results and complications in renal transplant recipients. Observations in the second decade. Transplantation. 1988;45(1):45-52.

39. Carvalho MF, Soares V. Hyperlipidemia as a risk factor of renal allograft function impairment. Clin Transplant. 2001;15(1):48-52.

40. Holdaas H, Fellström B, Cole E, et al. Long-term cardiac outcomes in renal transplant recipients receiving fluvastatin: the ALERT extension study. Am J Transplant. 2005;5(12):2929-2936.

41. Hjelmesaeth J, Jenssen T, Hagen M, Egeland T, Hartmann A. Determinants of insulin secretion after renal transplantation. Metabolism. 2003;52(5):573-578.

42. Kasiske BL, Snyder JJ, Gilbertson D, Matas AJ. Diabetes mellitus after kidney transplantation in the United States. Am J Transplant. 2003;3(2):178-185
43. Cosio FG, Pesavento TE, Kim S, Osei K, Henry M, Ferguson RM. Patient survival after renal transplantation: IV. Impact of post-transplant diabetes. Kidney Int. 2002;62(4):1440-1446.

44. Cosio FG, Kudva Y, van der Velde M, et al. New onset hyperglycemia and diabetes are associated with increased cardiovascular risk after kidney transplantation. Kidney Int. 2005;67(6):2415-2421.

45. Prasad GV, Huang M, Silver SA, et al. Metabolic syndrome definitions and components in predicting major adverse cardiovascular events after kidney transplantation. Transpl Int. 2015;28(1):79-88.

46. Moreira TR, Bassani T, de Souza G, Manfro RC, Gonçalves LF. Obesity in kidney transplant recipients: association with decline in glomerular filtration rate. Ren Fail. 2013;35(9):1199-1203.

47. Cannon RM, Jones CM, Hughes MG, Eng M, Marvin MR. The impact of recipient obesity on outcomes after renal transplantation. Ann Surg. 2013;257(5):978-984.

48. Armstrong KA, Campbell SB, Hawley CM, Nicol DL, Johnson DW, Isbel NM. Obesity is associated with worsening cardiovascular risk factor profiles and proteinuria progression in renal transplant recipients. Am J Transplant. 2005;5(11):2710-2718.

49. Baum CL, Thielke K, Westin E, Kogan E, Cicalese L, Benedetti E. Predictors of weight gain and cardiovascular risk in a cohort of racially diverse kidney transplant recipients. Nutrition. 2002;18(2):139-146.

50. van den Ham EC, Kooman JP, Christiaans MH, Nieman FH, van Hooff JP. Weight changes after renal transplantation: a comparison between patients on 5-mg maintenance steroid therapy and those on steroid-free immunosuppressive therapy. Transpl Int. 2003;16(5):300-306.

51. Woodle ES, First MR, Pirsch J, et al. A prospective, randomized, double-blind, placebo-controlled multicenter trial comparing early (7 day) corticosteroid cessation versus long-term, low-dose corticosteroid therapy. Ann Surg. 2008;248(4):564-577.

52. Feldman HI, Fazio I, Roth D, et al. Recipient body size and cadaveric renal allograft survival. J Am Soc Nephrol. 1996;7(1):151-157.

53. Streja E, Molnar MZ, Kovesdy CP, et al. Associations of pretransplant weight and muscle mass with mortality in renal transplant recipients. Clin J Am Soc Nephrol. 2011;6(6):1463-1473.

54. Molnar MZ, Streja E, Kovesdy CP, et al. Associations of body mass index and weight loss with mortality in transplant-waitlisted maintenance hemodialysis patients. Am J Transplant. 2011;11(4):725-736.

55. Segev DL, Massie AB, Schold JD, Kaplan B. If you're not fit, you mustn't quit: observational studies and weighing the evidence. Am J Transplant. 2011;11(4):652-653.

56. Huml AM, Sehgal AR. BMI, sex, and access to transplantation. Clin J Am Soc Nephrol. 2014;9(5):843-844.

57. Glanton CW, Kao TC, Cruess D, Agodoa LY, Abbott KC. Impact of renal transplantation on survival in end-stage renal disease patients with elevated body mass index. Kidney Int. 2003;63(2):647-653.

58. Nelson WK, Houghton SG, Milliner DS, Lieske JC, Sarr MG. Enteric hyperoxaluria, nephrolithiasis, and oxalate nephropathy: potentially serious and unappreciated complications of Roux-en-Y gastric bypass. Surg Obes Relat Dis. 2005;1(5):481-485.

59. Evans S, Michael R, Wells H, et al. Drug interaction in a renal transplant patient: cyclosporin-Neoral and orlistat. Am J Kidney Dis. 2003;41(2):493-496.

60. Praga M, Hernández E, Andrés A, León M, Ruilope LM, Rodicio JL. Effects of body-weight loss and captopril treatment on proteinuria associated with obesity. Nephron. 1995;70(1):35-41.

61. Rogers CC, Alloway RR, Alexander JW, Cardi M, Trofe J, Vinks AA. Pharmacokinetics of mycophenolic acid, tacrolimus and sirolimus after gastric bypass surgery in end-stage renal disease and transplant patients: a pilot study. Clin Transplant. 2008;22(3):281-291. 


\section{Publish your work in this journal}

Transplant Research and Risk Management is an international, peerreviewed open access journal focusing on all aspects of transplantation and risk management to achieve optimal outcomes in the recipient improving survival and quality of life. The journal welcomes submitted papers covering original research, basic science, clinical studies, reviews \& evaluations, guidelines, expert opinion and commentary, case reports and extended reports. The manuscript management system is completely online and includes a very quick and fair peer-review system, which is all easy to use. Visit http://www.dovepress.com/ testimonials.php to read real quotes from published authors.

\footnotetext{
Submit your manuscript here: http://www.dovepress.com/transplant-research-and-risk-management-journal
} 